\title{
19. HOW MUCH CLIMATIC INFORMATION DO WATER ISOTOPES CONTAIN?
}

\author{
A systematic comparison between the IAEA/GNIP isotope \\ network and the ECHAM 4 atmospheric general circulation \\ model
}

\author{
G. HOFFMANN, M. CUNTZ, J. JOUZEL \\ Institut Pierre Simon Laplace (IPSL), Paris, \\ and Laboratoire des Sciences du Climat et de l'Environnement (LSCE), \\ Orme des Merisiers, Gif sur Yvette, France
}

M. WERNER

Max-Planck-Institut fur Biogeochemie,

Jena, Germany

\section{Introduction}

In the last 50 years, the ${ }^{18} \mathrm{O} /{ }^{16} \mathrm{O}$ signature of meteoric water (in the following, $\delta_{18} \mathrm{O}_{\text {prec }}$ ) has become a key tracer intensively used both in hydrology and in palaeoclimatology. In palaeoclimatology, the original atmospheric signal, i.e. ${ }^{\mathrm{IS}} \mathrm{O}_{\text {prec }}$, is reconstructed by means of a variety of palaeo-archives such as ice cores, c s t r i e sediments, tree ring cellulose or speleothems. In both research fields, the understanding of the original isotope signal, before entering a hydrologic system or efore being archived, is essential.

To this end, a powerful modelling tool was developed about 20 years ago: Atmospheric General Circulation Models (AGCMs) fitted with water isotope diagnostics (Hoffmann et al., 1998; Joussaume et al., 1984; Jouzel et al., 1987). The fitting procedure is a relatively straightforward, although technically difficult process. The hydrologic cycle as described in these three-dimensional AGCMs has 
HOFFMANN et al.

Table 1 List of AGCMs which are equipped with a water isotope module Publications are given in order of the relevant time-scale

\begin{tabular}{|c|c|c|c|}
\hline AGCM & $\begin{array}{l}\text { Annual and seasonal } \\
\text { time scale }\end{array}$ & \begin{tabular}{|l|}
$\begin{array}{l}\text { Interannual time } \\
\text { scale }\end{array}$ \\
\end{tabular} & \begin{tabular}{|l|} 
Palaeo i.e. $>1000$ \\
years time scale
\end{tabular} \\
\hline LMD, Paris & Foussaume et al., 1984 & & $\begin{array}{l}\text { Joussaume and } \\
\text { Jouzel, } 1993\end{array}$ \\
\hline $\begin{array}{l}\text { GISS, } \\
\text { New York }\end{array}$ & $\begin{array}{l}\text { Fouzel et al., 1991; } \\
\text { Fouzel et al., } 1987\end{array}$ & $\begin{array}{l}\text { Cole et al., 1999; } \\
\text { Cole et al., 1993; } \\
\text { Vuille et al., } \\
\text { 2003a; 2003b }\end{array}$ & $\begin{array}{l}\text { Charles et al., } \\
\text { 1994; } \\
\text { Delaygue et al., } \\
\text { 2000a; } \\
\text { Delaygue et al., } \\
\text { 1999; } \\
\text { Delaygue et al., } \\
2000 \text { b; } \\
\text { Jouzel et al., } \\
2000 ; \\
\text { Jouzel et al., } \\
1994\end{array}$ \\
\hline $\begin{array}{l}\text { ECHAM, } \\
\text { Hamburg }\end{array}$ & Hoffmann et al., 1998 & $\begin{array}{l}\text { W e rn er a nd } \\
\text { Heimann, 2002; } \\
\text { This paper. }\end{array}$ & $\begin{array}{l}\text { Hoffmann and } \\
\text { Heimann, 1997; } \\
\text { Hoffmann et al., } \\
\text { 2000; } \\
\text { Werner et al., } \\
2000 \text { a; } \\
\text { Werner et al., } \\
2000 \text { b; } \\
\text { Werner et al., } \\
2000 \text { c }\end{array}$ \\
\hline $\begin{array}{l}\text { GENESIS, } \\
\text { Boulder }\end{array}$ & Mathieu et al., 2002 & & \\
\hline $\begin{array}{l}\text { MUC, } \\
\text { Melbourne }\end{array}$ & $\begin{array}{l}\text { Noon and Simmonds, } \\
2002 \mathrm{a} ; \\
\text { Noon and } \\
\text { Simmonds, } 2003\end{array}$ & $\begin{array}{l}\text { Noon and } \\
\text { Siinmonds, } \\
2002 \mathrm{~b}\end{array}$ & \\
\hline
\end{tabular}

to be replicated, and each time a phase transition is calculated in the model the corresponding fractionation process has to be taken into account to estimate the 
isotopic composition of the various water fractions. In this way, the water isotopes are computed solely depending on climate, with their variability simulated by the AGCM. The AGCM itself is constrained, depending on the time scale considered, by observed or reconstructed sea surface temperatures (SSTs), atmospheric greenhouse gas concentrations and solar insolation. To date, at least half a dozen modelling groups have followed this approach (see Table 1) and additional modelling groups are expected to build such an isotope module into their GCMs.

The focus of interest of the various scientists using the results of threedimensional water isotope models is different, according to their main working field and speciality.

GCM modellers, for example, are interested in an independent test of the parameterization of the model's water cycle. A variety of basically unobserved variables such as condensation temperatures, cloud thickness, evaporation rates, etc. influence the $\delta^{18} \mathrm{O}_{\text {prec }}$ signal. Therefore, comparison of modelled and observed water isotope signals presents a valuable test for this important part of the physics of AGCMs. Hydrologists, on the other hand, are increasingly applying their models to larger spatial scales. This typically involves the need to apply new and uncertain parameterization techniques and again calls for an independent and sensitive test procedure, as provided by water isotopes. Spatial scales of AGCMs and some hydrologic models are now sufficiently close to each other that a physical coupling will be feasible soon.

Finally, palaeoclimatologists certainly have the most vivid interest in a water isotope modelling tool that allows the interpretation of $\delta^{18} \mathrm{O}_{\text {prec }}$ not only in terms of local temperatures or precipitation rates but also in terms of atmospheric circulation and source region changes, for example.

Classically, palaeoclimatologists do the necessary calibration of an isotope palaeo-record using a modem analogue technique. They establish a relationship between regional $\delta^{18} \mathrm{O}_{\text {prec }}$ and climate parameter (for example annual $\mathrm{T}_{\text {surface }}$ ) and subsequently apply this modem spatial relationship to the temporal $\delta^{18} \mathrm{O}_{\text {prec }}$ series they have measured. However, it is well known that such modern analogue methods involve many uncertainties. The most important example of its failure is probably the application of the modem spatial $\delta^{18} \mathrm{O}_{\text {prec }} /$ temperature relationship in interpreting the ice core records in Central Greenland. Here, a number of independent studies have shown that, at least on a glacial/interglacial time-scale, the real temporal $\delta^{18} \mathrm{O}_{\text {prec }}$ /temperature slope is about half the modem spatial slope (Cuffey et al., 1995; Dahl-Jensen and Johnsen, 1986; Severinghaus et al., 1998). It is certainly one of the major successes of "isotopic AGCMs" that they were able to give a sound explanation for this de-calibration of the isotopic thermometer by simulating a strong shift in the seasonal distribution of precipitation under full glacial conditions (Werner et al., 2000c).

This Paper reports on advances in modelling water isotopes by means of GCMs during the last five years. After briefly summarizing the fractionation physics built into AGCMs (Section 2), we present results of the ECHAM "isotopic AGCM" integrated under boundary conditions corresponding to the 20th century. In Section 3 , we present a model/data comparison for the most recent version of the ECHAM 
AGCM, the cycle 4 version of the climate model of the Max-Planck Institut fur Meteorologie, Hamburg. In an earlier paper (Hoffmann et al., 1998), results of the cycle 3 version of the ECHAM model were compared with observations of the IAEA/GNIP network. Here, we did a systematic model evaluation of the ECHAM 4 version in T30 resolution on a seasonal to interannual scale. The model/data comparison presented here is designed to include "palaeo-isotope" series in the future and to extend this kind of study to the interdecadal and centennial time-scale.

\section{Model physics}

The ECHAM 4 model is documented in detail in Roeckner et al., 1996. Isotope physics was described in Hoffmann, 1995 and Hoffmann et al, 1998, and further results with the actual ECHAM 4 model are documented in Werner and Heimann, 2001 and Werner et al., 2000b, 2000c. Here we summarize briefly the way how the physics of water isotopes is, in principle, built into all existing "isotopic AGCMs".

According to Merlivat and Jouzel, 1979, isotopic fractionation at the ocean surface combines effects of equilibrium and kinetic fractionation. The scaled difference between $\delta \mathrm{D}$ and $\delta^{18} \mathrm{O}$ in meteoric water, $\mathrm{d}=\delta \mathrm{D}-8^{*} \delta^{18} \mathrm{O}$, the deuterium excess, sensitively depends on the non-equilibrium, kinetic fractionation at the ocean-atmosphere interphase.

This quantity is not discussed here, but in first order the above approach gives satisfying results for the deuterium excess simulated by AGCMs, (Jouzel et al., 1987, Delaygue et al., 2000b; Hoffmann et al., 1998; Werner et al., 2000a). Cloudinternal processes (condensation, evaporation) take place in isotopic equilibrium, and a fraction of falling raindrops is assumed to be in equilibrium with the surrounding water vapour, depending on the type of precipitation: $95 \%$ is in equilibrium for large-scale (typically extra-tropical) precipitation due to the comparably small droplet size and only $50 \%$ of the precipitation is in equilibrium if the precipitation is formed in convective events.

Though it is reasonable to assume that isotopic equilibrium is less complete in convective systems than in large-scale cloud systems, the actual values of the equilibration are not based on observations. In nature, equilibration might vary a lot between individual precipitation events. Further kinetic (non-equilibrium) processes take place during the formation of ice crystals at very cold temperatures (Jouzel and Merlivat, 1984) and during the fall of raindrops below the cloud base through a very dry atmosphere (Jouzel et al., 1987). In the ECHAM model, no fractionation takes place during evapotranspiration from the continental surface. Though certainly justified for plants this is a strong assumption for evaporation from bare soils and snow surfaces. The water isotopes were tracked in the model's soil hydrology and runoff. For further details on the incorporation of the water isotopes into AGCMs we refer to the original publications (Hoffmann, 1995; Joussaume, 1983; Jouzel et al., 1987). 


\section{Results}

\subsection{GLOBAL RELATIONSHIPS}

Comparing results of a GCM with observations is always a difficult task, as a spatially very heterogeneous data set can be compared in several different ways with gridded model results. Thus it is sometimes difficult to ascribe the differences between observations and model results clearly to model deficiencies or to the chosen method of comparison. Here we perform the datalmodel comparison strictly on the basis of the existing observational IAEA/GNIP network.
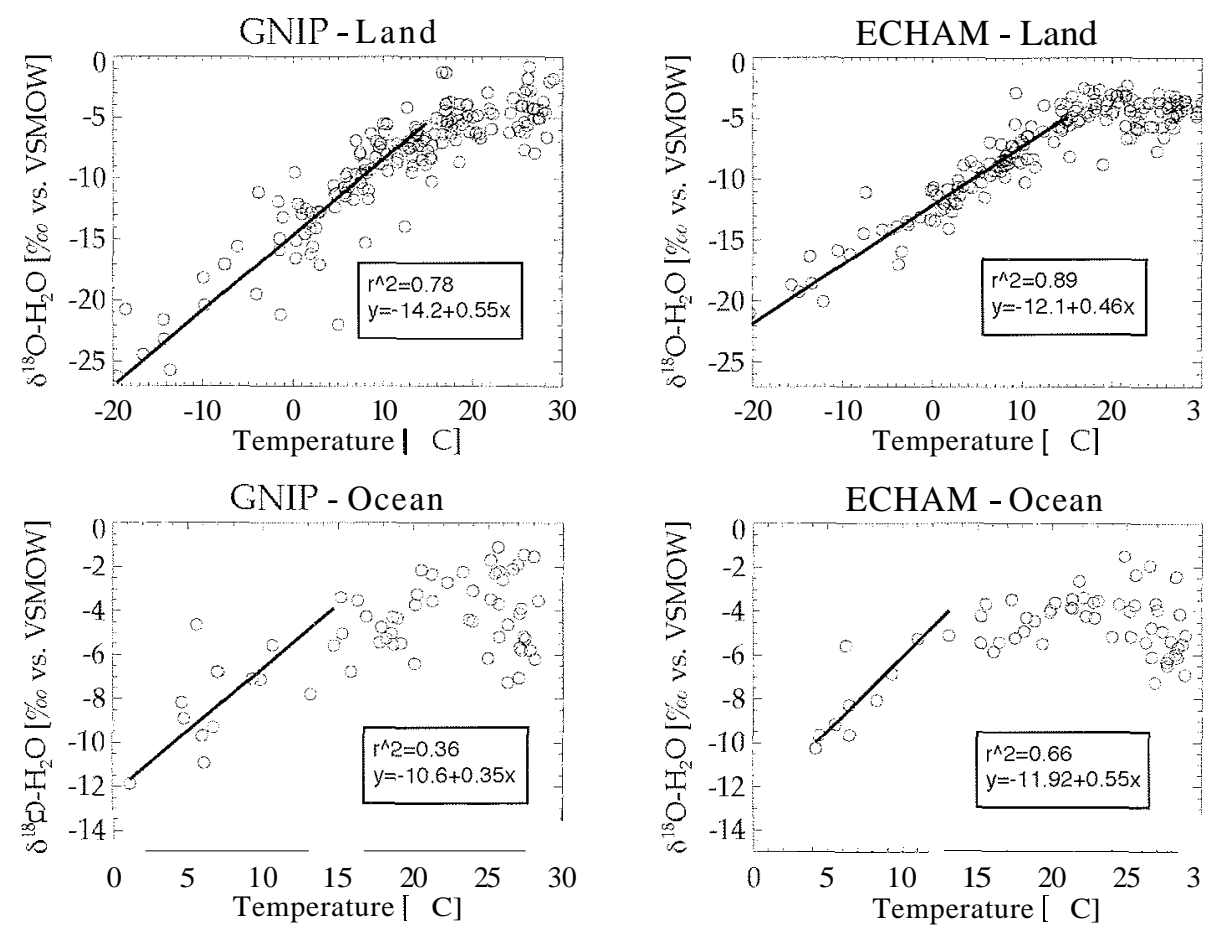

FIG 1 Comparison of the simulated and observed temperatureld ${ }^{18} O$ relationship \{annual mean) over land and over the ocean, respectively The simulation of the ECHAM 4 model was forced with observed SSTs for the period 1903-1993 The observations are exclusively from the GNIP/IAEA networks functioning since 1961 (http //isohis iaea org) Annual and monthly means of the model and of the observations were computed for the same time period, respecting gaps in the observations The linear correlations are calculated for a mean temperature $<15^{\circ} \mathrm{C}$ 
The ECHAM model was integrated in T30 spectral resolution (corresponding to a spatial resolution of $3.75^{\circ} \times 3.75^{\circ}$ and a model time step of 30 minutes) and monthly observations of the isotopes and the concurrent meteorological data were superimposed on the spatial grid of the model. If several observations existed within one grid cell we simply calculated the precipitation weighted arithmetic mean of the existing data. Monthly anomalies were only considered when at least four measurements per month existed. A 20th century simulation with the cycle version 4 of the ECHAM model was performed using realistic SST (SST data set provided by the United Kingdom Meteorological Office (Hurrell and Trenberth, 1999) and greenhouse gas forcing from 1903-1993 (IPCC, 1995). Model results were treated in the same way as the observations using exactly the months when observations were available.

Global spatial relationships between the water isotopes and near-surface temperature are calculated separately over the continents and over the oceans, respectively (Fig. 1, upper and lower panel). In contrast to the cycle 3 version (which overestimates the $\delta^{18} \mathrm{O}_{\text {prec }} / \mathrm{T}$ relation (Hoffmann et al., 1998) the model underestimates by about $15 \%$ the spatial isotopeltemperature relation over land. It is possible that this difference between the cycle 3 and 4 version of the ECHAM model is due to the fact that in this study we compare the results on the GNIP/IAEA observational grid.

The correlation $\left(\mathrm{r}^{2}\right.$ obs $=0.78 ; \mathrm{r}^{2}$ mode $\left.=0.89\right)$ and the point where the temperature control on the isotopes breaks down (at about $15^{\circ} \mathrm{C}$ ) are in good agreement with the observations. Over the ocean, continuous vapour recharge of air masses leads to the weakening of the isotopeltemperature relationship, which is correctly captured by the model.

The temperature threshold of about $15^{\circ} \mathrm{C}$ in the case of the "temperature effect" geographically corresponds to the boundary between mid- and low latitudes. This termination is probably triggered by the growing importance of convective precipitation. The intensity of convective events is only spuriously affected by surface temperature and, rather, is controlled by large-scale moisture confluence. In a simple Rayleigh distillation model, rainout intensity controls the isotopic signal and, consequently, it was suggested that in convective events the precipitation amount itself is inversely related to the water isotopic composition of the rain (Dansgaard, 1964). This inverse $\delta^{18} \mathrm{O}_{\text {prec }} /$ prec. relation, or "amount effect", appears only weakly when comparing annual means of precipitation amount and of the water isotope signal $\delta^{18} \mathrm{O}_{\text {prec }}$ for the GNIP stations (see Fig. 2): it is rather overestimated by the model.

Though the "amount effect" is clearly seen for selected stations and regions (for example, Rozanski et al., 1992; Rozanski et al., 1993) globally the precipitationwater isotope relationship is very noisy (in the observations and in the model). One could expect the amount effect to appear more clearly over the tropical ocean, since terrestrial stations are more influenced by atmospheric circulation, which occasionally brings a station under the influence of continental, and thus depleted, air masses. However, even when restricting our analysis to ocean stations with a mean temperature greater than $15^{\circ} \mathrm{C}$, the amount effect still shows up only weakly 
(Fig. 2). Even when computing the same $\delta^{18} \mathrm{O}_{\text {prec }} /$ prec. correlation on a monthly basis (not shown here) the amount effect does not appear much clearer on the global scale.

In a next step we compare monthly means of the water isotopes and temperature to validate the simulated seasonal cycle (Fig. 3). The modelled seasonal $\delta^{18} \mathrm{O}_{\text {prec }}$ /temperature relation is in good agreement with the observations. However, as for the spatial $\delta^{18} \mathrm{O}_{\text {prec }} /$ prec. relation (Fig. 2) the model underestimates the noise in the seasonal relation over the ocean.
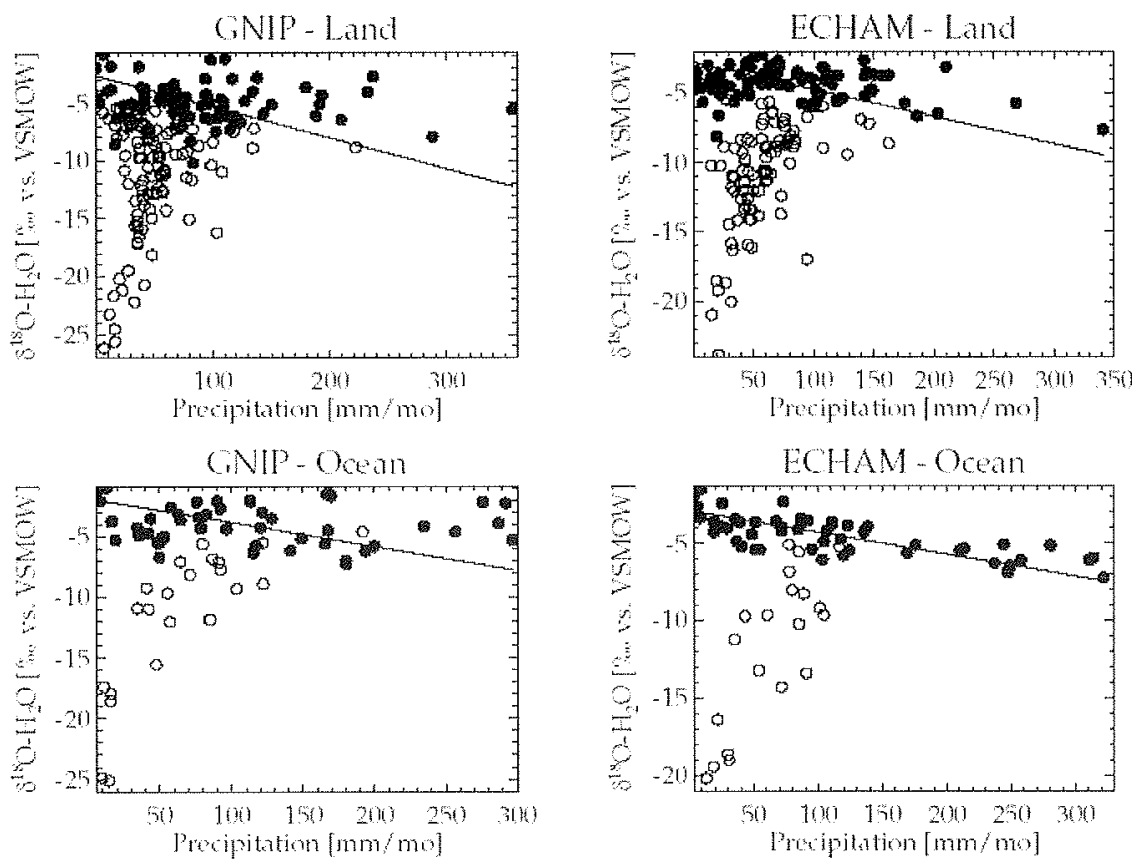

FIG. 2. Same as for Fig. I for the Precipitation/ $\delta^{8} \mathrm{O}$ relationship. This time, the correlations were computed for all stations/grid points with a mean temperature $>15^{\circ} \mathrm{C}$ (full circles)

\subsection{ANNUAL AND SEASONAL SCALE}

In order to identify regions and climatic zones where model results deviate significantly from the observed seasonal cycle we calculated phasing and amplitude of the simulated water isotope signal and compared them to observations (see Fig. 4). The phasing is evaluated by computing the correlation between simulated and observed monthly mean values. A correlation of 1 therefore means a perfect phasing of the simulated isotope cycle. In high northern and southern latitudes the 

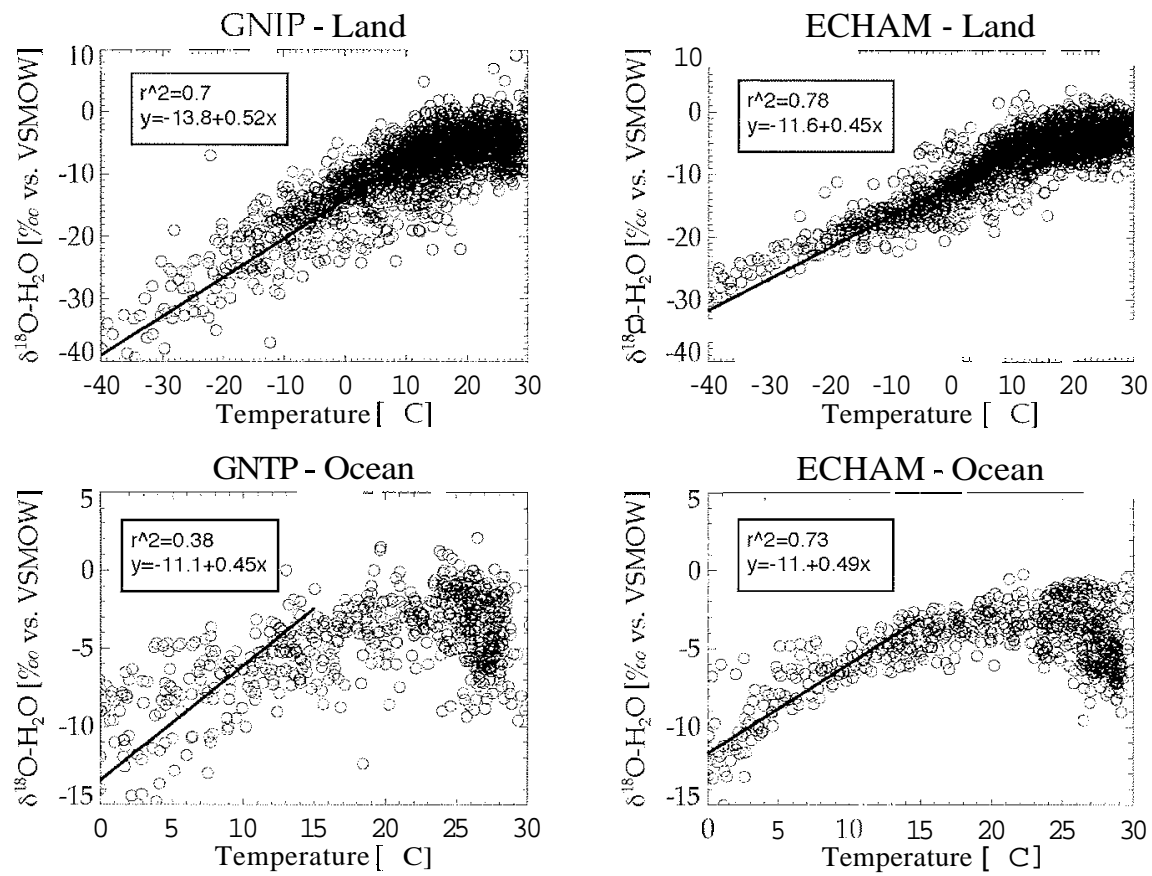

FIG 3 The temperature/ $\delta^{\text {\& }}$ O relationship for monthly means Correlations are computed for stations with a mean temperature $<15^{\circ} \mathrm{C}$

model quite accurately simulates the seasonal cycle $(r>0.7)$. In low latitudes the model occasionally does not reproduce the correct spatial extension and/or onset of monsoon precipitation (China). Generally, poor statistics (i.e. rare rain events) most probably is responsible for a comparably small con-elation in some dry areas (Sahel and the Mediterranean region). Equally the model has problems to simulate the precise position of the Inter-Tropical Convergence Zone, as is evident over the tropical Pacific and South America ( $\mathrm{r}$ sometimes $<0.3$ ). The strong rainfall within the ITCZ is typically associated with relatively depleted isotope values, which is why small shifts in its simulated position relative to the observations lead to a drastic worsening of the correlation. The amplitude of the seasonal cycle is evaluated in Fig. 4(b), which shows the relative deviation of the simulated from the observed seasonal amplitude:

$$
\text { Amplitude }=\left(\left(\operatorname{Max}^{\text {GNIP }}-\text { Min }^{\text {GNIP }}\right) /\left(\operatorname{Max}^{\text {ECHAM }_{-M i n}}{ }^{\text {ECHAM }}\right)-1\right) * 100 \text {. }
$$


where Max and Min refer to the maximum and minimum $\delta^{18} \mathrm{O}$ values of the longterm monthly means in the GNIP network and in the ECHAM simulation respectively.

Ideally the relative deviation of the simulated amplitude (Eq. (1)) would always be zero. In fact, at most GNIP stations the model indeed reproduces the observed amplitude within $20 \%$, and larger deviations can only be identified in regions with small seasonal amplitudes (Atlantic ocean sites). Clear spatial patterns can be found, for example, over Europe, where the model underestimates the seasonality in southern Europe and overestimates it in northern Europe.
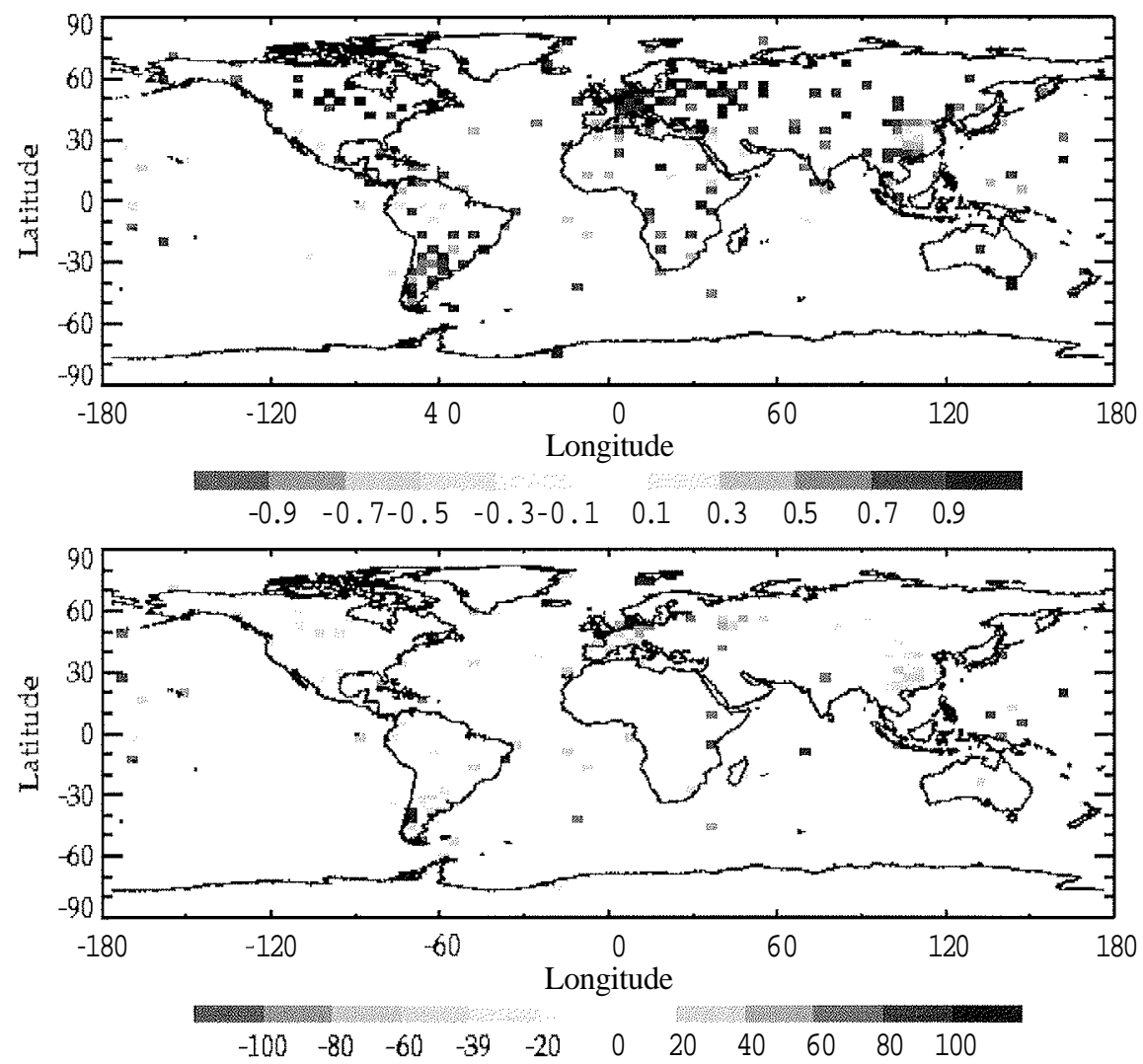

FIG 4 Phasing and amplitude of the simulated water isotope signal relative to the GNIP/IAEA observations The upper panel shows the non-normalized correlation between simulated and observed isotope signals (ideally based on 12 values) Perfect agreement between model and observations corresponds to $r=1$ The lower panel shows the reproduction of the seasonal amplitude ( $E q(1)) 100 \%$ con esponds to a perfect agreement between the model and the observations 


\subsection{INTERANNUAL TIME-SCALE}

As mentioned above, we restrict our analysis of interannual isotope/climate parameter relationships to the time period common to IAEAIGNIP measurements (i.e. excluding also all sampling gaps at individual GNIP stations) and model simulation, that is the period from 1961-1993. In Figs 5-8 correlations and slopes are presented between monthly anomalies of $\delta^{18} \mathrm{O}_{\text {prec }}$ and temperature or precipitation, respectively. Observed correlations between monthly anomalies of $\delta^{18} \mathrm{O}_{\text {prec }}$ and temperature are spurious, even in regions where long-term high-quality records exist, e.g. over Europe. Only locally does the correlation exceed $r>0.4$; this value does not improve even when we take into account the full GNIP/IAEA sampling period (and not just the period 1961-1993).

The result implies that typically more than $80 \%$ of the interannual isotope variability is controlled by factors other than local temperature variations. Important factors that might strongly affect the $\delta^{18} \mathrm{O}$ signal are changing moisture source regions and continental recycling rates, both known to mask a simple control of $\delta^{18} \mathrm{O}_{\text {prec }}$ by local climate parameters. This result has already been mentioned in several studies analysing interannual variability in isotopic models and in the GNIP observational network (Cole et al., 1999; Vuille et al., 2003b).

In summary we are faced with a variety of locally and temporally highly variable factors influencing the $\delta^{18} \mathrm{O}$ signal and thus, a single dominating factor, at least on the interannual scale discussed here, is difficult to identify. Though most $\delta^{18} \mathrm{O}_{\text {prec }}$ /temperature correlations are positive, in low latitudes (Southeast Asian monsoon system) sometimes they become negative. Such unphysical relations are caused by an overshadowing amount effect, i.e. strongest rainfall at warm summer temperatures creates rainout conditions which give rise to more negative isotope signals. Observed $\delta^{18} \mathrm{O}_{\text {prec }}$ temperature slopes vary also quite substantially, between $0.1 \%$ per ${ }^{\circ} \mathrm{C}$ and $0.6 \%$ per ${ }^{\circ} \mathrm{C}$ over Europe and North America for example. A reasonable calibration for palaeostudies based on these findings is not feasible.

\subsection{PREC./TEMPERATURE}

The ECHAM model (Fig. 6) overestimates the influence of interannual temperature variations on the water isotopes by at least a factor of 2 (Figs. 5 and 6). Simulated $\delta^{18} \mathrm{O}$ correlations are spatially more homogeneous, and a much clearer land/sea contrast can be found in the model results compared to the GNIP observations. Over Europe and North America, correlations vary between 0.4 and 0.6 whereas over the oceans correlations are close to 0 . The simulated $\delta^{18} \mathrm{O}_{\text {prec }}$ /temperature slopes spread around the simulated global spatial slope of $0.5 \%$ per ${ }^{\circ} \mathrm{C}$. Basically the model comes much closer to the ideal case of a constant isotope/local temperature relationship, spatially as well as on various time-scales. Different possible explanations are at hand for this deviation of the model from the GNIP observations on the interannual time scale. First, it is of course possible that the way we parameterized temperature control on the water isotopes in the model is incorrect. 

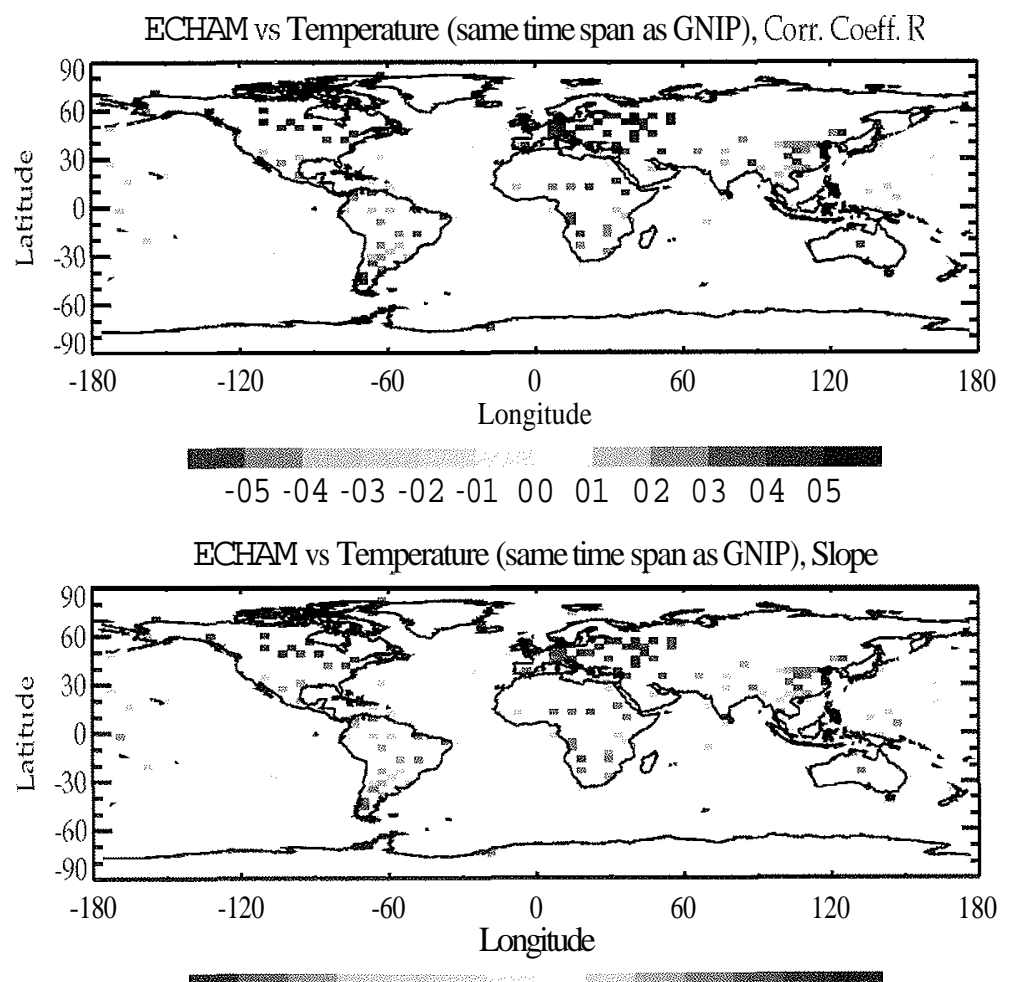

$-0.6-0.5-0.4-0.3-0.2-0.10 .00 .10 .2 \quad 0.3 \quad 0.40 .50 .6$

FIG 5 Correlation between temperature and $\delta^{8} O$ and the corresponding slope for the GNIP/IAEA data for the period 1961-1994

However, we then have to explain how it is possible that the model is adequate on the annual and seasonal time scale but fails on the interannual scale. An alternative explanation has to do with the GNIP observational network. Besides possible problems with the quality of the isotope measurements, there is also the issue of how we treat several stations within one grid point. Over Europe in particular, we merge monthly anomalies of stations with considerably different meteorological regimes (e.g. north and south of the Alps) into one grid point record. Moreover, the quality and length of GNIP data records differ significantly (IAEA, 1992). In fact, single long-term stations or even several stations from one region under a similar atmospheric influence (e.g. the Swiss stations discussed in Rozanski et al., 1993) show stronger interannual correlations between the isotopes and temperature than we calculate here for the GNIP network (Fig. 5).

Figures 7 and 8 show the same analysis as in Figs 5 and 6 but for the 
relation between the water isotopes and precipitation amount ("interannual amount effect"). In the observations (Fig. 7) and in the ECHAM simulation (Fig. 8), the $\delta^{18} \mathrm{O}_{\text {prec }}$ /Prec. correlation is nearly everywhere negative.
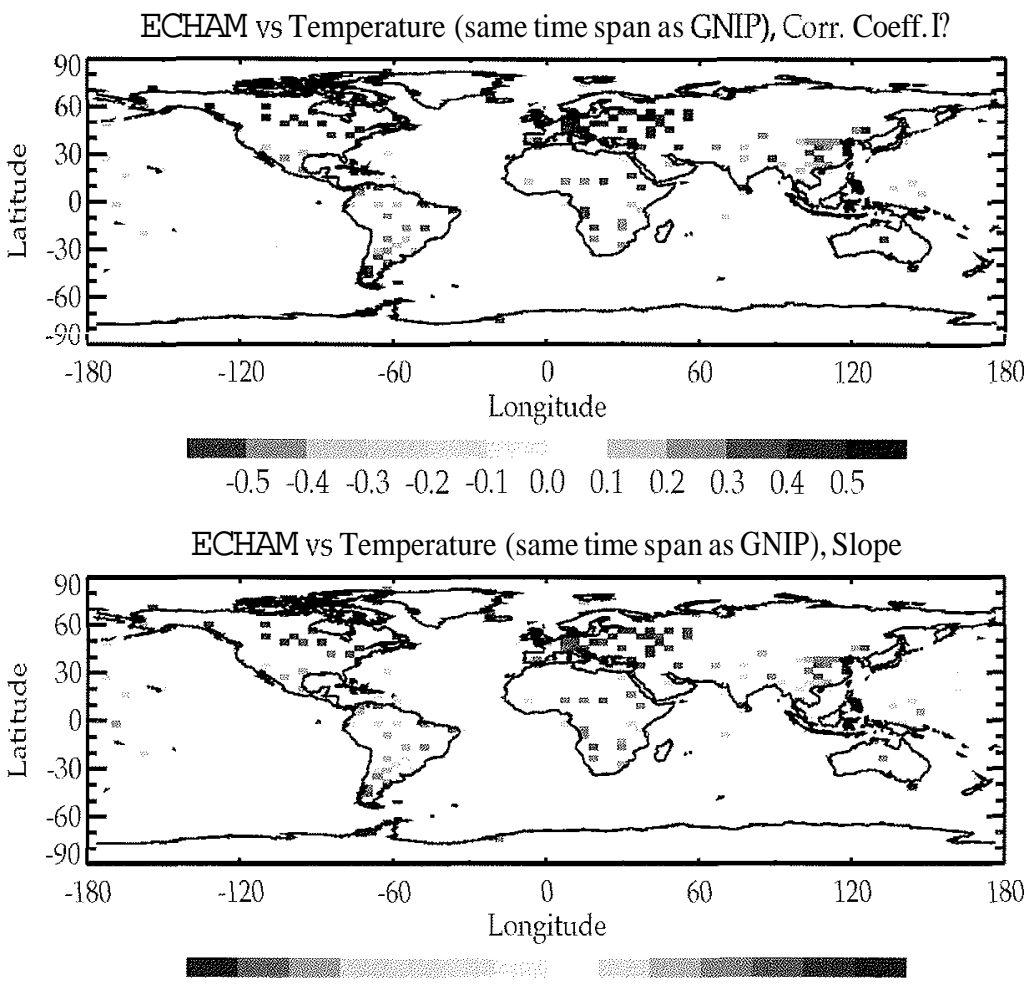

$\begin{array}{lllllllllllll}-0.6 & -0.5 & -0.4 & -0.3 & -0.2 & -0.1 & 0.0 & 0.1 & 0.2 & 0.3 & 0.4 & 0.5 & 0.6\end{array}$

FIG. 6. Same as Fig. 5 for the ECHAM 4 model

At least in the model, but to some extent also in the observations, the tropics show a stronger influence of precipitation on the isotope signal. In high latitudes, this anti-correlation is an artefact of the (weak) anti-correlation between temperature and precipitation amount which is caused thermodynamically. Anomalously warm (cold) years tend to be slightly wetter (dryer). At the same time, warm (cold) temperature anomalies are responsible for higher (lower) isotope values (Figs 5 and 6). The anti-correlation is thus a sort of artefact of the temperature effect on the one hand and a weak control of temperature on the amount of precipitation on the other hand. In low latitudes, however, the anti-correlation between the isotopes and precipitation is a direct consequence of the amount effect. The model again overestimates the anti-correlation and shows more clearly than the observation 
regions where precipitation variability leads to comparably strong isotope signals. For example, precipitation anomalies linked with the ENSO phenomenon (over the West-Pacific warm pool, the Central Pacific and over South America) are nicely anti-correlated with isotope anomalies $(r<-0.6)$.

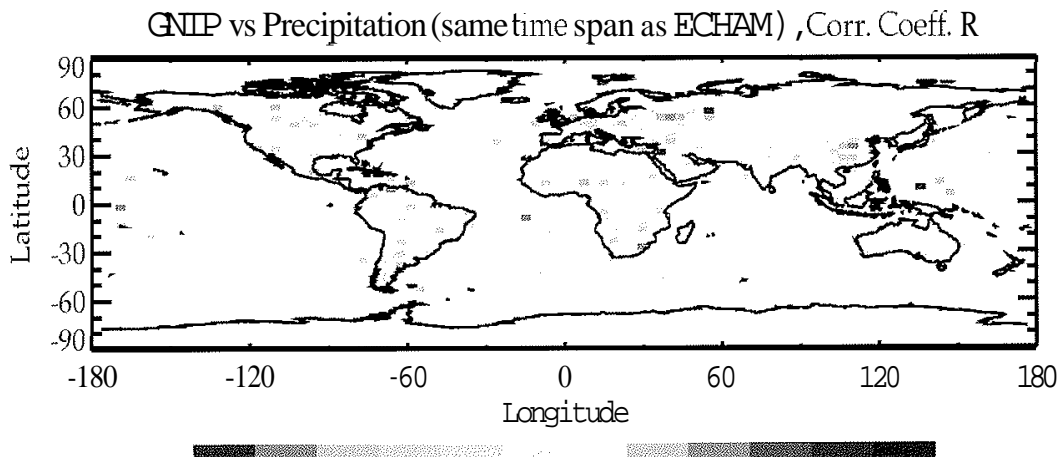

$\begin{array}{lllllllllll}-0.5 & -0.4 & -0.3 & -0.2 & -0.1 & 0.0 & 0.1 & 0.2 & 0.3 & 0.4 & 0.5\end{array}$

GNIP vs Precipitation(same time span as ECHAM) ,Slope

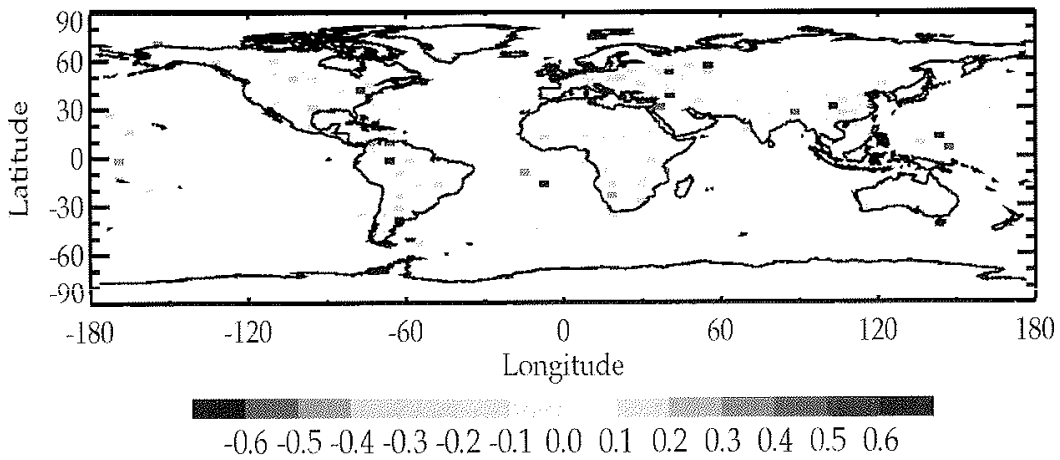

FIG 7 Correlation between precipitation and $\delta^{8} O$ and the corresponding slope for the GNIP/IAEA data for the period 1961-1994

\section{Discussion and conclusion}

As was already shown in previous publications, "isotopic AGCMs" are able to simulate reasonably well the seasonal cycle and the spatial distribution of water isotopes. On this time scale, deviations between the model and the GNIP observations are typically less than $20 \%$ of the phasing and the amplitude of the seasonal cycle. On an interannual scale, however, the water isotopes are only weakly controlled by local temperature/precipitation changes in most regions of the world. Computed correlations between the isotopes and local climate are overestimated by the ECHAM 4 model, and, moreover, the simulated spatial coherency of these 
correlations is greater than in the IAEA/GNIP network: the model appears to define more clearly than the observations whether in a given region the temperature effect or the amount effect governs the isotope variations in precipitation. It is certainly an objective for future work to explain this finding. One could imagine that with higher spatial resolution the model becomes spatially more incoherent. To test this hypothesis we need long-term integrations in high resolution (T106, corresponding to a $1^{\circ}$ resolution). Furthermore, such a response of the AGCM might be modeldependent, and similar simulations should be performed with other existing "isotopic" AGCMs to test this possibility (see Table 1).
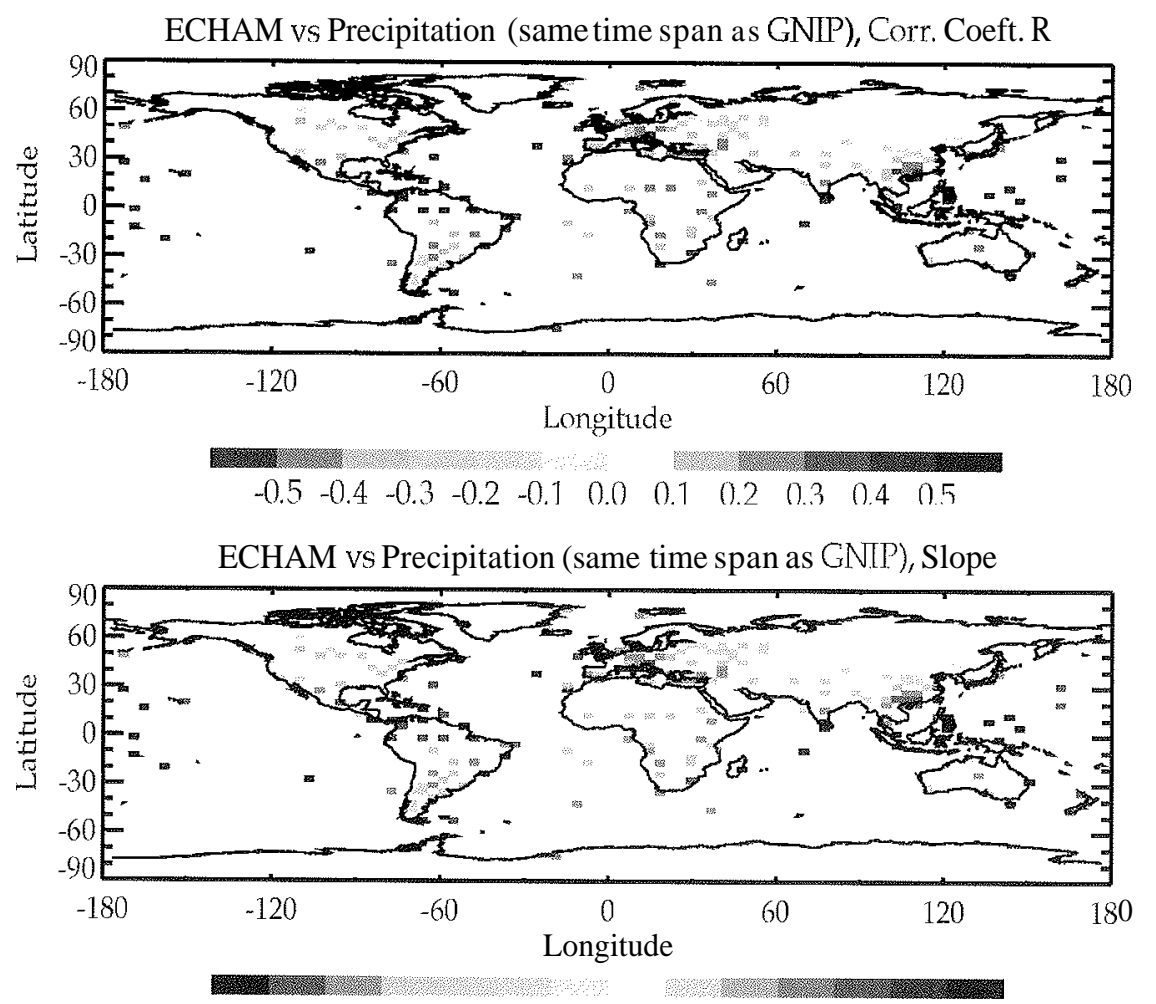

$-0.6-0.5-0.4-0.3-0.2-0.1 \quad 0.0 \quad 0.1 \quad 0.20 .3 \quad 0.40 .5 \quad 0.6$

FIG. 8. Same as Fig. 5 for the ECHAM 4 model.

However, there are hints that various factors controlling the water isotopes on an interannual time scale (source and trajectory changes, recycling rate, etc.) cancel each other out to some extent when changing to the decadal and inter-decadal scale. This cancelling then leads to a clearer relation of $\delta^{18} \mathrm{O}_{\text {prec }}$ to local climate parameters. For example, the decadal signal-to-noise ratio of Andean isotope records 
was shown to be extremely favourable, and the resulting mean Andean isotope signal was demonstrated to be controlled by large-scale displacements of the Hadley-Walker circulation, probably triggered by ENSO variability in the Central Pacific (Bradley et al., 2003; Hoffmann, 2003; Hoffmann et al., 2003).

Another example of an successful interpretation of high resolution isotope series in terms of climate parameters stems from Greenland. White et al., 1997, demonstrated that one needs several ice core isotope records from the same spot to reduce post-depositional noise and to construct a representative isotope signal for Central Greenland. This signal is still influenced by several factors including local temperature, North Atlantic SST and pressure gradients, notably those associated with the North Atlantic Oscillation (NAO). Moreover, when dealing even more carefully with seasonality in these Central Greenland isotope records, Vinther et al., 2003, was even able to establish an excellent relationship between the mean Greenland isotope signal and the NAO, which itself of course already combines a number of atmospheric processes (not only temperature, but also precipitation and circulation changes).

The latter two examples aim to demonstrate that a reasonable interpretation of long-term changes (which means in the context of this discussion an interannual to centennial scale) is feasible given two key conditions are fulfilled.

- A mean regional isotope signal must be established. The aim is to reduce several noise factors in the isotope series, such as archive effects (for example post-depositional effects in ice core records) or small-scale variance (the leading pattern of the different isotope records in the Andes or in Central Greenland was shown to be more representative than each individual series). Even for the GNIP isotope data, as was mentioned above, more attention should be given to this point than was the case in this work. For example, we averaged the existing GNIP data into one grid point record, though there are considerable differences in terms of station length and quality as well as microclimatic differences (Alpine stations north and south of the Alps from high and low altitude were merged into one record).

- The full complexity of the isotope signal must be taken into account, e.g. the influence of source region and trajectory changes. This can be achieved by using "isotopic" AGCMs. The weak relation between interannual climate and isotope variations is the reason why there are no palaeo-isotope series in the databases used to reconstruct millennial temperature trends (Jones et al., 2001; Mann et al., 1998). These studies are based on the assumption that a specific proxy, typically tree ring width and density series, project significantly on observed interannual temperature variability over the period where direct meteorological observations exist (end of the 19th and the 20th century). In the next step the established (non-linear) transfer functions are used to deduce, for example, northern-hemisphere temperature trends since about 1000 A.D. from the entire proxy time series. These works lead to the important conclusion that the 20th century is probably the warmest since at least 1000 years, due to anthropogenic greenhouse gas emission (Mann et al., 1998). A critical point in 
these studies is the applicability of the computed transfer functions within a longer time frame than the interannual scale on which the calibration has been established, i.e. it essentially raises the question of the stability of atmospheric tele-connections. For tree ring analysis, there is also a non-trivial problem arising from the aging of trees, for which a reasonable correction has to be applied. Finally, the calibration period, basically the 20th century, is already influenced by a changing climate and changing atmospheric $\mathrm{CO}_{2}$ concentrations (Briffa et al., 1998). The latter factor is obviously of major importance for living trees and might also influence their sensitivity to temperature changes.

An estimation of inter-decadal to centennial climate variability in the last millennium, independent of the Mann-approach through water isotope analyses, seems possible in the future We suggest that long (-millenial) palaeo-isotope records are introduced into the same model/data framework as has been done here for the IAEA/GNIP network. This means that long-term integrations of "isotopic ocean-atmosphere" GCMs have to be carried out with realistic boundary conditions of the last millennium (solar insolation, volcanic eruption, etc.). Variability and trends of observed and simulated isotope signals on an inter-decadal to centennial time scale will then provide us with an independent estimate of climate variability during the last millennium.

\section{REFERENCES}

Bradley, R., Vuille, M., Hardy, D.R, Thompson, L.G. (2003) Low latitude ice core record Pacific sea surface temperatures. Geophysical Research Letters 30 (4),10.1029/2002GL016549.

Briffa, K.R., Schweingruber, Y.H., Jones, P.D., Osborn, T.J., Shiyatov, S.G., Vaganov, E.A. (1998) Reduced sensitivity of recent tree-growth to temperature at high northern latitudes. Nature 391, 678682.

Charles, C.D., Rind, D., Jouzel, J., Kostcr, R.D., Fairbanks, R.G. (1994) Glacial-Interglacial changes in moisture sources for Greenland: Influence on the ice core record of climate. Science 263, 508-511, 1994.

Cole, J.E., Rind, D., Webb, R.S., Jouzel, J, Healy, T. (1999) Climatic controls on interannual variability of precipitation $\delta^{18} \mathrm{O}$ : The simulated influence of temperature, precipitation amount, and vapour source region. J. Geophys. Res. 104, 14,223-14,235.

Cole, J.E., Rind, D., Fairbanks, R.G. (1993) Isotopic responses to interannual variability simulated by an AGCM. Quat. Sci. Rev. 12, 387-406.

Cuffey, K.M., Clow, G.D., Alley, R.B., Stuiver, M., Washington, E.D., Saltus, R.W. (1998) Large Arctic temperature change at the glacial-holocene transition. Science 270, 445-458.

Dahl-Jensen, D., Johnsen, S.J. (1986) Palacotemperatures still exist in the Greenland ice sheet. Nature $320,25-252$.

Dansgaard, W. (1964) Stable isotopes in precipitation. Tellus 16, 436-468

Delaygue, G., Jouzel, J., Masson, V., Roster, R.D, Bard, E. (2000a)Validity of the isotopic thermometer in central Antarctica: limited impact of glacial precipitation seasonality and moisture origin. Geophysical Research Letters 27 (17), 2677-2680. 
Delaygue, G., Masson, V.,V., Jouzel, J. (1999) Climatic stability of the geographic origin of Antarctic precipitation simulated by an atmospheric general circulation model. Annals of Glaciology 29, 45-48.

Delaygue, G., Masson, V., Jouzel, J., Koster, R.D., Heal), R.J. (2000b) The origin of Antarctic precipitation: a modelling approach. Tellus 52 (B), 19-36.

Hoffmann, G. (1995) Wasserisotope im allgemeinen Zirkulationsmodell ECHAM, Universität Hamburg, Hamburg.

Hoffmann, G.(2003) Taking the pulse of the tropical water cycle. Science 301, 776-777.

Hoffmann, G., Heimann, G.(1997) Water isotope modeling in the Asian monsoon region. Quat. Int 37, 115-128.

Hoffmann, G., Masson, V., Jouzel, J (2000) Stable water isotopes in atmospheric general circulation models. Hydrologic Processes 14, 1385-1406.

Hoffmann, G., Ramirez, E. E., Taupin, J.D., Francou, B., Ribstein, P., Delmas, R,. Dürr, H., Gallaire, R., Simôes, J., Schotterer, U., Sticvenard, M., Werner, M. (2003) Coherent isotope history of Andean ice cores over the last century. Geophysical Research Letters 30 (4), 10.1029/2002GL014870.

Hoffmann, G., Werner, M., Heimann, M. (1998) The water isotope module of the ECHAM atmospheric general circulation model - a study on time scales from days to several years. J. Geophys. Res. 103, 16,871-16,896.

Hurrell, J., Trenberth, K. (1999) Global sea surface temperature and analyses: Multiple problems and their implications for climate analysis, modeling, and reanalysis. Bulletin of the American Meteorological Society, 80 (12), 2661-2678, 1999.

International Atomic Energy Agency (1992) Statistical Treatment of Data on Environmental Isotopes in Precipitation. Technical Reports Series No. 331, IAEA, Vienna.

Intergovernmental Panel on Climate Change (2001) The Science of Climate Change. Report of Working Group 1, Cambridge University Press, Cambridge, UK, available online at www.ipcc.ch .

Jones, P.D., Osborn, T.J., Briffa, K.R. (2001)The evolution of climate over the last millenium. Science $292,662-667$.

Joussaume, J. (1983) Modelisation des cycles des espèces isotopiques de l'eau et des aerosols d'origine desertique dans un modele de circulation générale de l'atmosphère. Université Pierre et Marie Curie, Paris.

Joussaume, J., Sadourny, R., Jouzel, J. (1984) A general circulation model of water isotope cycles in the atmosphere. Nature 31I, 24-29.

Joussaume, S., Jouzel. J., (1993) Palaeoclimatic tracers: an investigation using an atmospheric general circulation model under ice age conditions, 2, water isotopes. J. Geophys. Res. 98, 2807-2830.

Jouzel, J., Hoffmann, G. Koster. R.D., Masson, V.(2000) Water isotopes in precipitation: Data/model comparison for present-day and past climates. Quaternary Science Review 2000 (19), 363-379.

Jouzel, J., Koster. R.D., Suozzo,R.J. Russell, G.L. (1994) Stable water isotope behavior during the Last Glacial Maximum: A general circulation model analysis. J. Geophys. Res. 99, 25791-25801.

Jouzcl, J., Merlivat,L. (1984) Deuterium and oxygen 18 in precipitation, modelling of the isotopic effects during snow formation. J. Geophys. Res. 89. 11749-11757.

Jouzel, J., Koster, R.D., Suozzo, R.J., Russsel, G.L., White, J.C.W., Broecker, W.S. (1991) Simulations of the HDO and ${ }^{18} \mathrm{O}$ atmospheric cycles using the NASA GISS GCM: Sensitivity experiments for present-day conditions. J. Geophys. Res. 96, 7495-7507.

Jouzel, J., Russsel, G.L., Suozzo, R.J., Koster. R.D., White, J.C.W., Broecker, W.S. (1987) Simulations of the HDO and ${ }^{18} \mathrm{O}$ atmospheric cycles using the NASA GISS general circulation model: The seasonal cycle for present-day conditions. J. Geophys. Res. 92, 14739-14760. 
Mann, M.E., Bradley, R.S.,Hughes, M.K. (1998)Global-scale temperature patterns and climate forcing over the past six centuries. Science 392, 779-787.

Mathieu, R., Pollard, D., Cole, J.E., White, J.W.C, Webb, R.S. (2002) Simulation of stable water isotopes variations by the GENESIS GCM for modem conditions $J$ Geophys Res 107 (D4), doi,10.1029/2001JD900255.

Merlivat, L., Jouzel, J., (1979) Global climatic interpretation of the deuterium-oxygen-18 relationship for precipitation. J. Geophys. Res. 84, 5029-5033.

Noon, D., Simmonds, I. (2000a) Annular variations in moisture transport mechanisms and the abundance of $\delta^{18} \mathrm{O}$ in Antarctic snow. J Geophys. Res. 107 (D7), 4742, doi, 10.1029/2002JD002262, 2002a.

Noon, D., Simmonds, I., (2000b) Associations between $\delta^{18} \mathrm{O}$ of water and climate parameters in a simulation of atmospheric circulation for 1979-1995. Journal of Climate 15 (22), 3150-3169.

Noon, D., Simmonds, I. (2004) The sea-ice control on water isotope transport to Antarctica and implications for ice core interpretation, submitted to J. Geophys Res.

Roeckner, E., Arpe, K., Bengtsson, L., Christoph, M., Dümenil, L., Esch, M., Giorgetta, M, Schlese, U., Schulzweida, U. (1996) The Atmospheric General Circulation Model ECHAM-4: Model Description and Simulation of Present-Day Climate. Max-Planck Institut fur Meteorologie, Hamburg.

Rozanski, K., Araguas-Araguas, L., Gonfantini, R. (1992) Relation between long-term trends of oxygen18 isotope composition of precipitation and climate. Science 258, 981-985.

Rozanski, K., Araguas-Araguas, L., Gonfantini, R. (1993) Isotopic patterns in modern global precipitation. Climate Change in Continental Isotopic Records (P.K. Swart, K.C. Lohmann, J. MacKenzie, S. Savin, Eds) AGU, Washington, D.C., 1-3.

Severinghaus, J., Sowers, T., Brook, E.J., Alley, R.B., Bender, M.L. (1998) Timing of abrupt climate change at the end of the Younger Dryas interval from thermally fractionated gases in polar ice. Nature 391. 141-146.

Vinther, B.M., Johnsen, S.J., Andersen, K.K., Clausen, H.B., Hansen, A.W. (2003) NAO signal recorded in the stable isotopes of Greenland ice cores. Geophysical Research Letters 30 (7) 1387, doi,10.1029/2002GL016193.

Vuille, M., Bradley, R., Healy, R., Werner, M., Hardy, D.R., Thompson, L.G., Keimig, F. (2003a) Modelling $\delta^{18} \mathrm{O}$ in precipitation over the tropical Americas: 2. Simulation of the stable isotope signal in Andean ice cores. J. Geophys. Res. 108 (D6), 4175, doi, 10.1029/2001JD002039.

Vuille, M., Bradley, R., Werner, M., Healy, R., Keimig, F. (2003b) Modelling $\delta^{18} \mathrm{O}$ in precipitation over the tropical Americas: I. Interannual variability and climatic controls, J. Geophys. Res. 108 (D6), 4174, doi, 10.1029/2001JD002038.

Werner, M., I-leimatin, M. (2001) Modelling interannual variability of water isotopes in Greenland and Antarctica, J. Geophys. Res. 107 (D1), doi,10.1029/2001JD900253.

Werner, M., Heimann, M., Hoffmann, G. (2001) Isotopic composition and origin of polar precipitation in present and glacial climate simulations. Tellus B,53(1), 53-71,2001.

Werner, M., Mikolajewics, U., Hoffmann, G., Heimann, M. (2000b) Possible changes of $\delta^{18} \mathrm{O}$ in precipitation caused by a meltwater event in the North Atlantic. J. Geophys. Res. 105 (D) , 10,16110,167 .

Werner, M., Mikolayewicz, U., Heimann, M., Hoffmann, G. (2000c) Borehole versus isotope temperatures in Greenland: Seasonality does matter. Geophys. Res. Lett. 27 (5), 723-726.

White, J.W.C., Barlow, L.K., Fisher, D.A., Grootes, P.M., Jouzel, J., Johnsen, S.J., Stuiver, M., Clausen, H. (1997) The climate signal in the stable isotopes of summit, Greenland snow: results of comparisons with modem climate observations. J. Geophys. Res. 102 (C12), 26425-26439. 